\title{
Development of a Complex of Self-Cooling Bearing Systems as a Fundamentally New Direction in Construction on Permafrost
}

\author{
Vadim Passek $^{1, *}$, and Aleksandr Tsernant ${ }^{2}$ \\ ${ }^{1,2}$ Industrial University of Tyumen, 625001 Volodarskogo str. 38, Tyumen, Russia
}

\begin{abstract}
The article describes a new direction in constructing on permafrost (the new constructions are suggested) - a complex of selfcooling bearing systems, which is based on the winter transfer of cold from the atmosphere directly into the deeper layers of the soil by natural air convection. It presumes the spontaneous activating of cooling process in winter period and deactivating of it during summer. The complex is designed as a system of cavities and channels disposed at different angles to the vertical, which are partially located in the base soil and partially contact the open air environment. They may be closed and open for the access of the outside air, besides, all the elements of the system or some of them are the bearing structures of the construction object.
\end{abstract}

\section{Introduction}

Over $60 \%$ of Russian territory is situated in the zone of permafrost. These are the territories where the major natural resources are located. Their development determines the viability of the national economy, therefore, these regions require development, including the construction of residential and industrial facilities, transport systems. The relevance of this, in particular, is determined by the Presidential Decree № 537 of May 12, 2009 "Russian National Security Strategy until 2020", which involves the development and implementation of innovative scenarios for development of the natural, and especially the energy resources, of the Arctic zone of Russia, that covers 140 degrees of longitude in northern latitudes of the Eurasian continent.

Permafrost is a good base for buildings and transport systems, but only if the frost persists during operating period. If soils start to thaw, they represent a flowing mass, totally unsuitable for use as bases.

Permafrost soil may consist of layers of buried ice, soil ice ( $80 \%$ of which is ice), saline soils that freeze only at low negative temperatures. And the frozen ground conditions are getting worse northward. To compensate these negative impacts, it is necessary that after the construction works, the desired low temperature of permafrost is provided during the entire operating period. Although building regulations allow to build on permafrost in

\footnotetext{
Corresponding author: tgasu.passek.vadim@,mail.ru
} 
accordance with two principles: preserving permafrost (principle 1) and letting it thaw (principle 2). The latter can be regarded only as an exception. It is applicable only to soils that do not lose strength properties during thawing -both directly under the structure, and in the adjacent soil masses. It is important to emphasize that thawing of a single soil body can cause the degradation of permafrost in neighboring areas, which can lead to major deformation processes not only of the structure itself, but of the whole built-up area. Furthermore, if a pile foundation zone starts thawing, the underlying layers of permafrost will thaw to a plastic-frozen (deformable) state which will gradually lead to the deformations of the entire soil body along with the piles. Thawing of the soil upper layers dramatically reduces the soil resistance to horizontal loads. Therefore, when building on permafrost, one should always try to achieve at least the preservation of permafrost, although lowering its temperature is better.

\section{Review}

In natural conditions the permafrost has formed in regions with a negative annual average temperature of air. At the same air temperature, the permafrost temperature and even presence depend on the surface layers in winter and summer. Construction of roads, cities, various facilities causes the sharp changes of conditions on the soil surface: there occur the areas with increased thickness of snow cover (which prevents the entry of the cold in winter), the vegetation cover is disturbed (which increases the heat input to the soil in summer), there occur the facilities with year round positive temperature, the regime of surface and ground water changes, etc. As a result, the frost starts either thawing (which reduces the load bearing capacity of soils), or even degrading.

Construction science and practice have been evolving for thousands of years beyond the permafrost zone. And no wonder that builders tried to use the past experience in the zone of permafrost when they faced it only at the turn of the XIX and XX centuries. And the endless deformations, fractures, accidents began to happen.

On the permafrost, the layout of a structure should be different! So the research and development work were started.

To compensate the defrosting influence of the facilities in Russia, Canada and the United States, a range of different measures has been developed [1, 2].

The efforts of the developers of these measures primarily were directed towards the formation of the best conditions for the heat transfer at the surface. One of the main measures - the ventilated underfloor space. In addition, different forms of insulation, riprap and other were suggested. Thus, the range of surface cooling measures had been formed, which in their nature were similar to factors, acting in a natural environment. This class of measures (generally very large and subdivided) can be considered to be formed according to the coverage of many different areas of practical applicability. We call it the first step of the theory and practice of constructing on permafrost.

But these measures turned out to be not enough in a large number of cases. Firstly, if the frost is formed over the centuries in natural conditions, these terms are not acceptable for conditions of building the real facilities (much shorter terms are required). Besides, some internal sources of heat appeared (e.g. heat pipelines). Under such circumstances, there occurred the necessity of rapid introduction of cold directly into the deep soil layers. In other words, there occurred a need to develop a class of deep cooling measures. This class of measures forms the second step of the theory and practice of constructing on permafrost, which expands the opportunities for construction by many times.

A range of this class measures has been developed: the liquid cooling systems of S.I. Gapeev [3], V.I. Makarov [4] or the vapor-liquid systems of Long [5], which were transformed into a range of variants and new versions in Russia [6]. All of them appear to 
be vertical or inclined pipes filled with different refrigerants and partially buried in the soil, partially protruding outward above the ground. The transfer of cold into the soil occurs only in winter. Each of these systems has its advantages, disadvantages and scope of rational application. However, all of them are located in the zone of engineering structure, but not inside of the structure itself, which means they tend to be some foreign body to it, the "medication". The mentioned installations can be very effectively used for technological purposes: for single initial freezing of the soil bodies, or during the operating period - for example, for eliminating the expected or unexpected thawing of soils [7-12].

Without belittling the mentioned projects, it can be assumed that the problem cannot be considered fully solved if the facility is "sick" and requires "medications", which are environmentally unsafe (as they contain kerosene, freon, etc.), non-durable, unreliable. Another thing is - if the facility is "healthy" and itself contributes to the desired regulation of the temperature regime of the bases soil.

\section{Description of the research and developed design}

The designed Complex of self-cooling bearing systems is based on the winter transfer of cold from the atmosphere directly into the deeper layers of the soil by natural air convection. It presumes the spontaneous activating of cooling process in winter period and deactivating of it during summer. The complex is designed as a system of cavities and channels disposed at different angles to the vertical, which are partially located in the base soil and partially contact the open air environment. They may be closed and open for the access of the outside air, besides, all the elements of the system or some of them are the bearing structures of the construction object.

The simplest and most developed part of the complex is a CSRIC thermal-control bearing. Figure 1 presents the exterior of the bridge with thermal-control bearings, and the principle of their operation is shown in Figure 2.

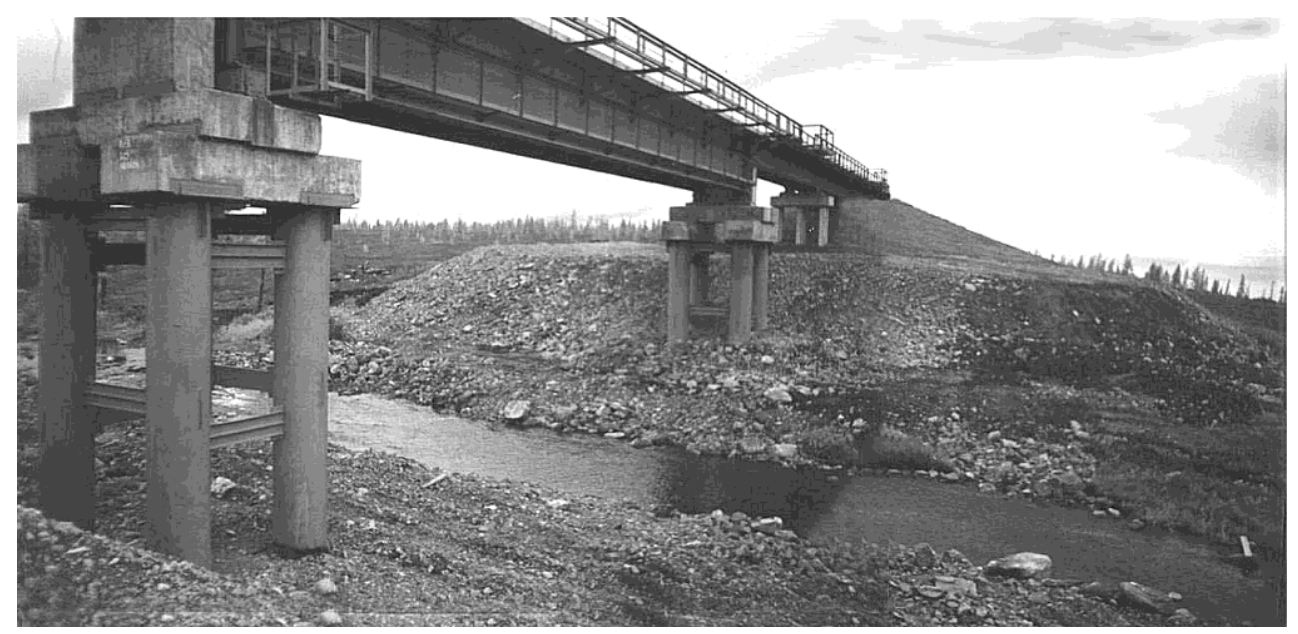

Fig. 1. Exterior of the bridge with thermal-control bearings. 


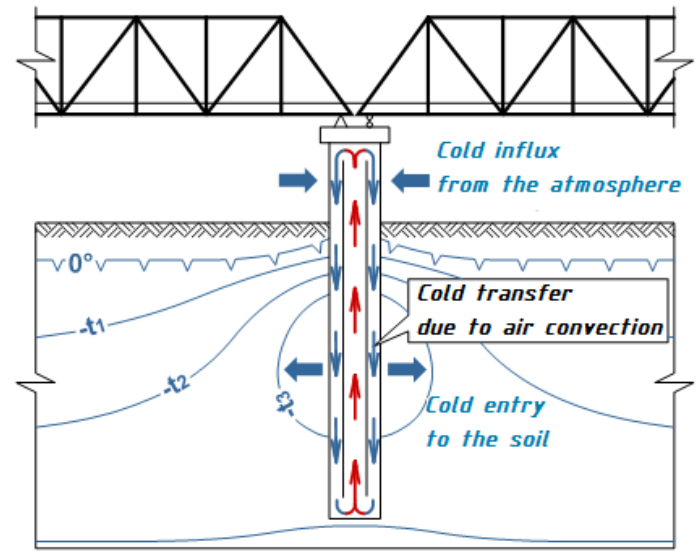

Fig. 2. The operation principle of thermal-control bearing of the bridge.

Fig. 3 is a schematic diagram of a cooling system in a building constructed on a boxshaped reinforced concrete foundation with intercommunicating air cavities. The upper chamber is located in the zone of the outer air. Warm air goes up the right pipe, then goes down the left pipe and enters the lower chamber being already cold.

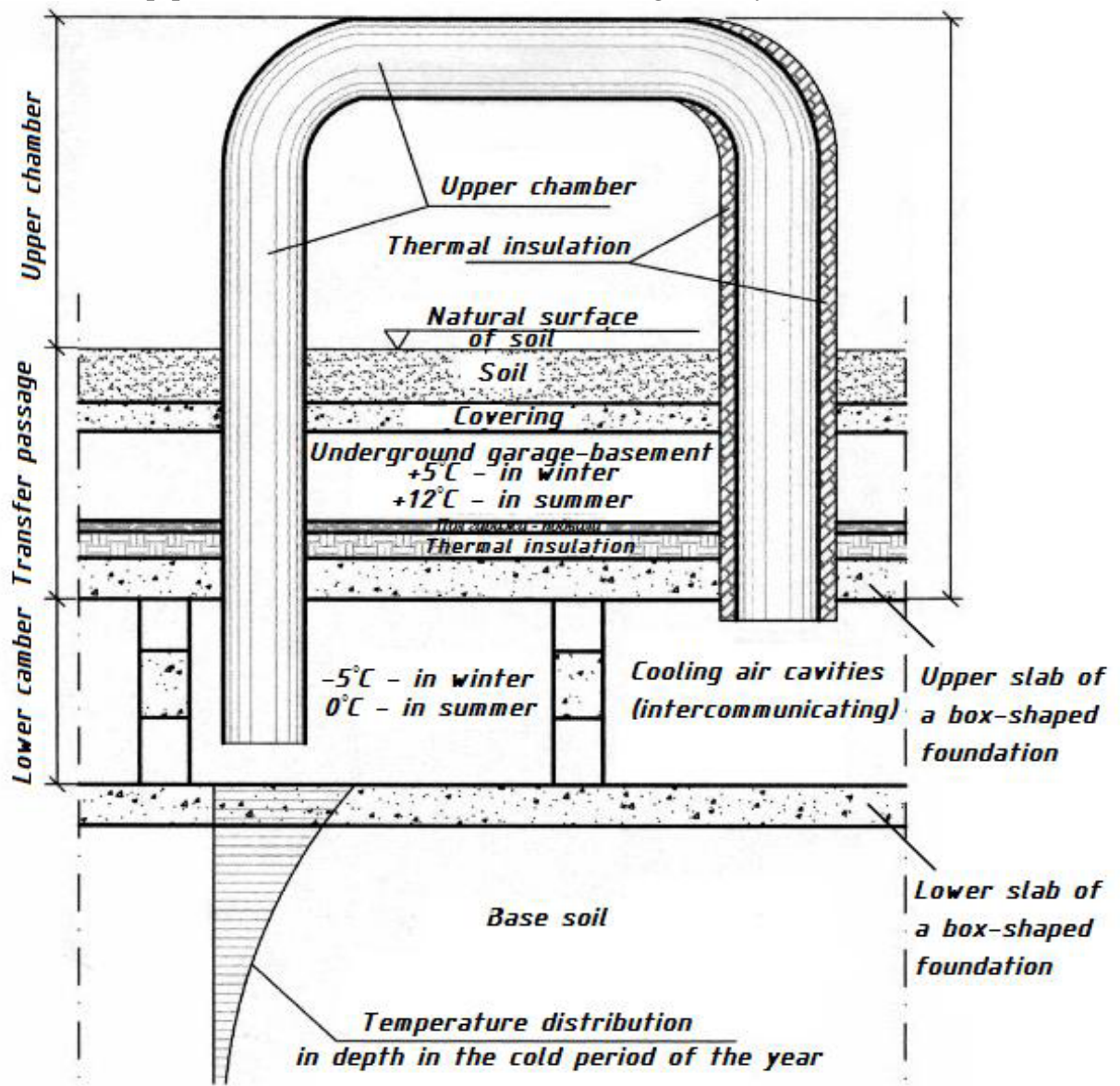

Fig. 3. Scheme of a cooling system in the building on a slab foundation. 
Fig. 4 shows a cooling system based on a combination of vertical and horizontal heat fluxes. In winter, the cold air causes convection in the underlying layer of rock by passing through the through-cavity.

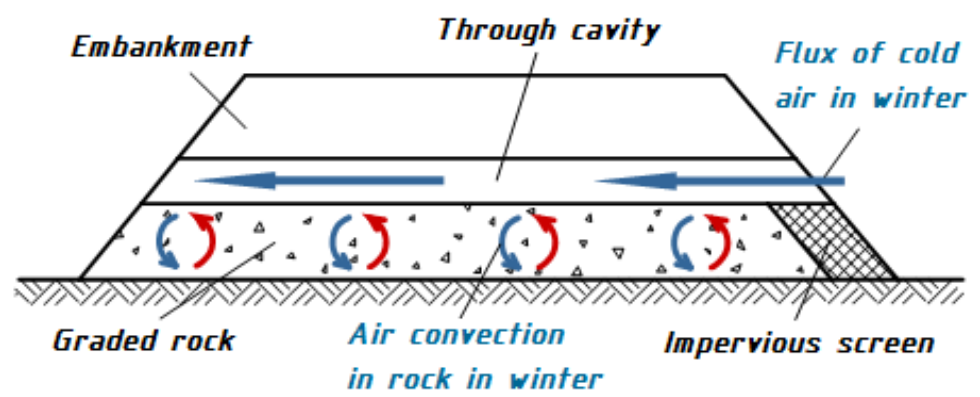

Fig. 4. The cooling system for the embankment.

Fig. 5 illustrates a cross-section of the oil pipeline transiting the steep bank of the river with the bedding of the plastic frozen soils. The air cooling system is also used here. The pipeline is located directly in the air cavity.

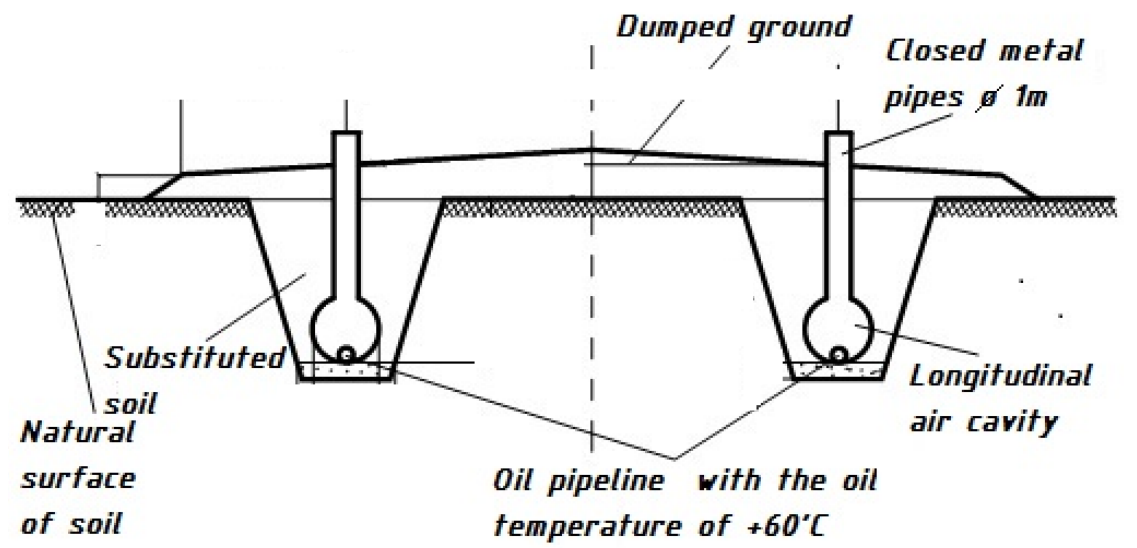

Fig. 5. The cross-section of the pipeline cooling system.

To determine the effectiveness of deep cooling in comparison with the surface cooling, a series of calculations were conducted, which involved comparing the speed of freezing the defrosted soil for a number of settlements in different climatic zones. The results were presented in the form of a diagram shown in Fig. 6. It can be seen that with the annual average reduced temperature of air (further AARTA) ta $=-10^{\circ} \mathrm{C}$, it takes the same amount of time to freeze the thawing soil for both surface cooling and deep cooling. So to ease the comparison, this value was taken as the time unit. When the AARTA increases, the rate of two curves changes. The curve of the surface cooling shoots up dramatically at AARTA above $-4^{\circ} \mathrm{C}$, indicating the fall of its effectiveness, while the deep cooling curve begins to acquire a slope only when the AARTA reaches positive temperatures. This suggests that short-term or global climate warming does not have a significant effect on the effectiveness of the deep cooling. The diagram is divided into zones in accordance with the borders of usage of the two cooling types.

Over the past forty years, dozens of different systems have been developed. The most notable designs are reflected in works [13-20]. 


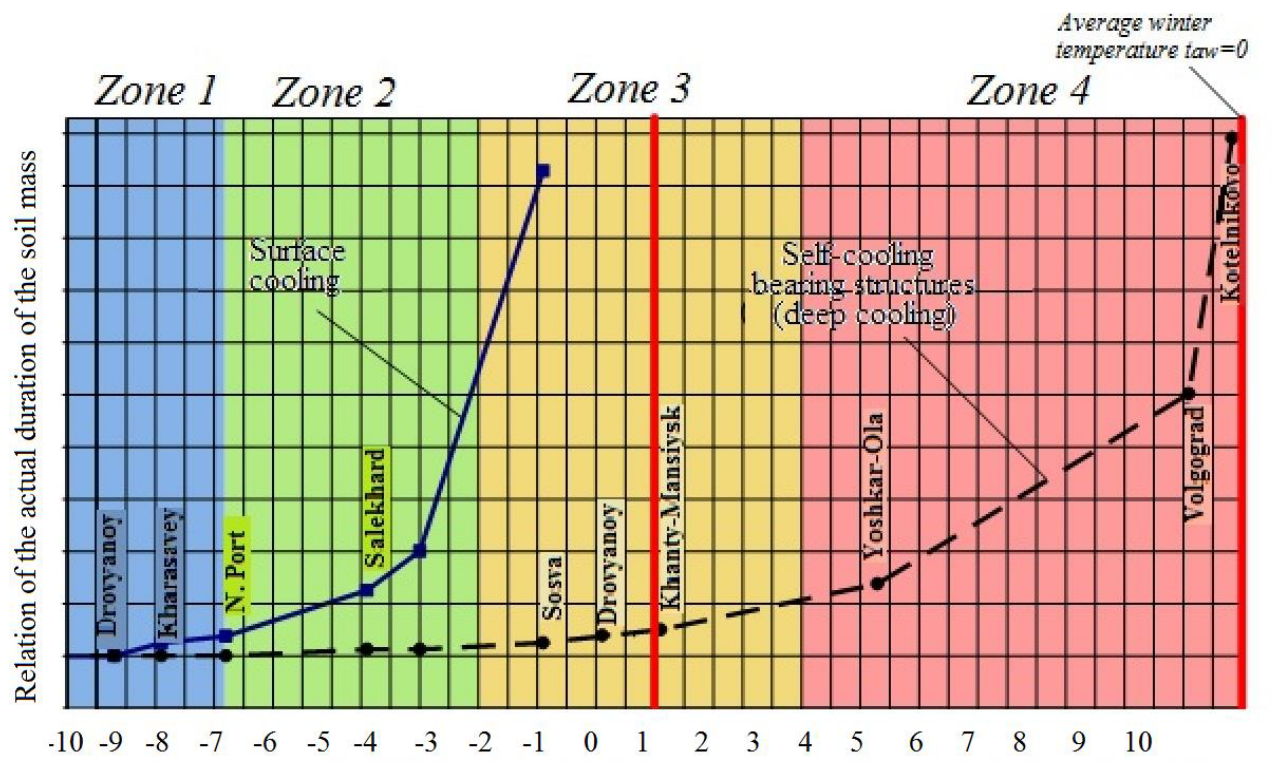

Averagereduced temperature of air (with a glance to solar radiation and evaporation from the surface), ta,

Fig. 6. Dependency diagram duration of the soil mass freezing with respect to the annual average reduced air temperature ta for the surface and deep coolings.

zone 1 - area of the equal effectiveness of the surface and deep coolings, zone 2 - area of the preferential use of the deep cooling, zone 3 - area of the deep cooling use only, zone 4 - area of the theoretically possible use of the deep cooling.

\section{Conclusion}

When designing the complex, the following has been developed: the theory of the soils deep cooling by natural air convection (in particular, 2 doctoral theses and 4 candidate's theses were defended, which were entirely or partially devoted to the analyzing issue); a set of specific structural and technological solutions; 27 patents were received; 23 scientific articles and a monograph were published; long-term (25 years) observations of the actual bridges built with the developed technical solutions, were conducted; 8 regulatory and guidance documentations were developed that allow to make calculations and designs.

The complex of the self-cooling bearing systems for the first time solves the problem of deep cooling by the fact that the constructed facility does it itself during the whole period of its operation. The complex is resistant to the global warming and offers new possibilities for construction technology and monitoring. It sums up the 45 year-period of the corporate authors' work, and marks the establishment of the theory of this issue (the theory of deep cooling by natural air convection), as well as the establishment of a large number of specific structural and technological solutions, which open the potential for new types of structures in relation to the permafrost conditions (Fig. 7). 


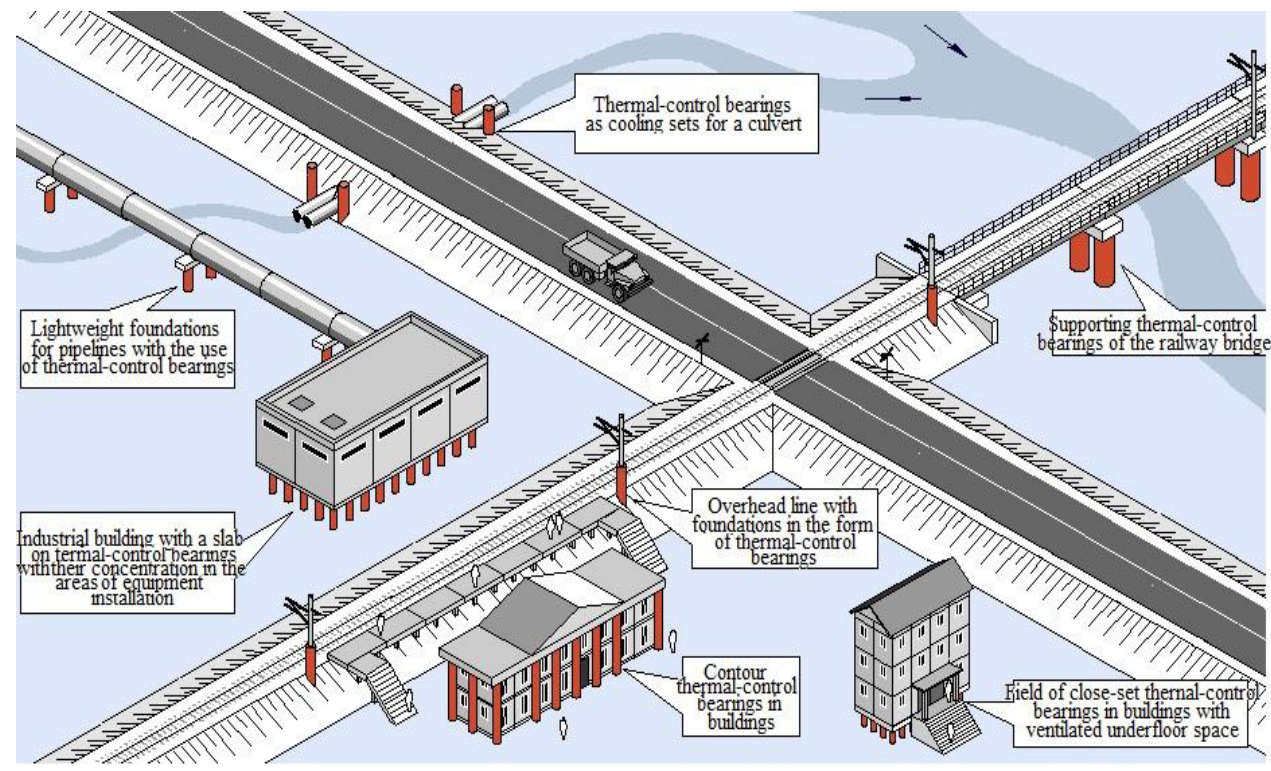

Fig. 7. Possible application areas of the self-cooling bearing systems complex in construction.

One can assume that this project pushed a significant leap forward and formed the second stage of the theory and practice of constructing on permafrost, which is defined by class of the deep cooling systems.

\section{References}

1. V. Passek, Sb. nauchnykh trudov JSC TSNIIS, 213 (2002)

2. A. Tsernant, Vestnik TyumGASU, 4, 10 - 15 (2015)

3. S. Gapeev, Ukreplenie merzlykh osnovaniy okhlazhdeniem (Stroyizdat, 1999)

4. V. Makarov, Termosifony v severnom stroitel'stve (Nauka, Novosibirsk, 1999)

5. E. Long, Means for Maintaining Permafrost Foundations. Pat. USA. № 3, 217, 791, 165-45 (1964)

6. R. Bayasan, Termostabilizatsiya grunta $v$ osnovanii ob"ektov gazotransportnykh system «Teplomassoobmen - MMF. Mezhdunarodnyy forum», 34 - 37 (1988)

7. V. Passek, A. Nabokov, M. Baev, T. Maltseva, V. Bai, I. Palavoshev, Vestnik TyumGASU, 4, 33 - 42 (2015)

8. V. Passek, M. Baev, A. Nabokov, I. Palavoshev,, A. Babukh, V. Bai, Vestnik TyumGASU, 4, 43 (2015)

9. V. Passek, V. Gerasimov, V. Rudenko, V. Dubinin, V. Passek, I. Kozlov, A. Odrinskiy, R.F. Patent 91723 (2009)

10. V. Passek, V. Gerasimov, V. Velichko, V. Rudenko, I. Kozlov, A. Odrinskiy, R.F. Patent 103542 (2010)

11. V. Passek, V. Gerasimov, I. Kozlov, B. Drobyshevskiy, V. Velichko, R.F. Patent 110758 (2011)

12. A. Che, Z. Wu, P. Wang, Soils and Foundations, 54(4) 639-647 (2014)

13. Y. Wang, H. Jin, G. Li, Cold Regions Science and Technology, 126, 10-21 (2016)

14. M. Wei, C. Guodong, W. Qingbai, Cold Regions Science and Technology, 59(1), 3-11 (2009)

15. V. Passek, I. Palavoshev, V. Velichko, G. Poz, M. Paskov, R.F. Patent 136446 (2013)

16. V. Passek, I. Palavoshev, M. Paskov, R.F. Patent 147446 (2014) 
17. V. Passek, I. Palavoshev, A. Nabokov, A. Babukh, M. Baev, V. Bai, R.F. Patent. (2015)

18. V. Passek, M. Baev, A. Nabokov, A. Babukh, V. Velichko, I. Palavoshev, G. Poz, V. Bai, R.F. Patent 156932 (2015)

19. V. Passek, A. Nabokov, I. Palavoshev, T. Maltseva, A. Kraev, A. Babukh, V. Andreev, R.F. Patent 156217 (2015)

20. T. Maltseva, A. Nabokov, A. Chernykh, Procedia Engineering, 117, 239-245 (2015) 